\title{
Polarised infrared microspectroscopy of edge-oriented graphene oxide papers
}

\author{
Mark D. Frogley ${ }^{a, *}$, Congwei Wang ${ }^{b}$, Gianfelice Cinque ${ }^{a}$ and Asa H. Barber ${ }^{b}$ \\ ${ }^{a}$ Diamond Light Source, Harwell Science and Innovation Campus, Chilton, OXON, OX11 \\ ODE, U.K
}

${ }^{b}$ Department of Materials, School of Engineering and Materials Science, Queen Mary University of London, Mile End Road, London E1 4NS, U.K

*Corresponding author e-mail: mark.frogley@diamond.ac.uk. Tel: +44 1235778721

\begin{abstract}
We have performed FTIR transmission microspectroscopy on graphene oxide papers oriented with the nominal lattice planes parallel to the infrared optical axis. By polarising the IR light for samples of this geometry, spectral contributions of oriented oxide species are isolated from broad convoluted bands. Analysing the data alongside previous works, including experiments where samples were perturbed by reduction, dehydration and deuteration, we tabulate the most likely assignments for the observed spectral bands.
\end{abstract}

Keywords: Graphene oxide, FTIR, Infrared, Absorption spectroscopy

\section{Introduction}

Graphene oxide (GO) is a widely studied material due to its potential as a pre-cursor for large scale solution processing of graphene devices as well as the additional functionality offered by the oxide species. The mechanical properties of GO are comparable with graphene but incorporation of GO as a reinforcement into polymers promises enhanced composite performance from direct chemical bonding between the phases, which is considerably more difficult for the more chemically inert graphene or carbon nanotubes [1-4]. As an electronic material, most applications are based on the high in-plane conductivity of reduced graphene oxide ( $\mathrm{rGO}$ ), which is improving rapidly towards the ideal case of graphene as methods to oxidise graphite and reduce graphene oxide with minimal defects are developed [5-10]. Lower quality rGO papers have already been shown to be useful in flexible supercapacitors [11-12]. Recently, a stable semiconducting form of rGO (graphite epoxide) has been produced [13], which may be important in a new carbon based era of electronics. Analogous to metal-organic frameworks (MOFs), using the oxide functionalities as controllable reaction centres for making graphene oxide frameworks (GOFs) for hydrogen storage and other applications requiring a large surface-to-volume ratio has also been demonstrated [14].

For many of these applications, the key unresolved issue is accurate characterisation and control of the oxygen functionalities and defects. The most common chemical method for producing GO, based on Hummers method [15], incorporates large scale nanoholes and a wide variety of functional groups including hydroxyls, carboxyls, epoxies and ketones, as well as lattice defects. IR absorption spectroscopy is a sensitive and widely employed method for quantifying these structures, with absorption bands strong enough to be measured even at the single or few-layer level. Oxide groups and adsorbed molecules produce rich mid-IR spectra, highly complementary to Raman spectroscopy that is sensitive to the graphite lattice modes and lattice defects and so often used for assessing the degree 
of reduction in GO. Analysis of the complex IR spectra is, however, difficult as the vibrational bands are broadened and convolved by the large numbers of unique molecular configurations present. Several workers have recorded in situ IR spectra during controlled perturbations of graphene and graphite oxides, mostly aimed at understanding different reduction treatments, and this data gives valuable insight into the molecular contributions to the spectra [8, 16-17]. In general, however, there is tremendous variety in the samples produced and spectra obtained - indeed at best, as-produced GO can be described as a metastable material [18]. Vibrational band assignments are inconsistent and therefore combining different perturbations and measurement techniques is vital to understand the complexity of these materials.

In this work, polarised transmission FTIR microspectroscopy is used to determine spectral contributions from oriented groups in graphene oxide papers. Since there is no definable inplane direction in GO paper, the samples are oriented with the nominal sheet planes parallel to the IR beam direction and thin sections are used to allow adequate transmittance. Strong orientation of $\mathrm{O}-\mathrm{H}, \mathrm{C}-\mathrm{O}$ and $\mathrm{C}=\mathrm{O}$ bonds is indentified, and where possible, assigned to specific chemical groups taking into account the other available experimental and theoretical work in the literature.

\section{Experimental}

\subsection{Production of GO paper}

GO papers were prepared following a modified Hummers method as described in our previous work [19]. Briefly, a mixture of sulphuric acid, sodium nitrate and potassium permanganate was used to oxidise graphite, which was then cleaned and sonicated to produce individual sheets of graphene oxide with an average length ranging from $\sim 1 \mu \mathrm{m}-100$ $\mathrm{nm}$. The aqueous solution of sheets was filtrated over several days to produce graphene oxide papers 30-60 $\mu \mathrm{m}$ thick with the sheet planes predominantly oriented along the plane of the paper as shown in figure 1. To produce thin sections for transmission IR absorption measurements, the papers were mechanically clamped between two pieces of low density polyethylene (LDPE) and microtomed at room temperature with a steel blade to various thicknesses between 1-10 $\mu \mathrm{m}$. This clamping method, shown schematically inset in figure 2 , was used to avoid chemical alteration or contamination of the GO from embedding agents. Difficulties retrieving intact samples meant that only a few usable samples were obtained, and in these cases the LDPE was still electrostatically bound to the GO (figure 2). The thin samples $\sim 1-3 \mu \mathrm{m}$ had an orange/brown appearance in visible transmitted light and a peak IR absorbance of order 1 , which is considered suitable for the subsequent IR measurements. Thicker samples appeared dark brown-black and the broadband losses were too high to obtain good quality spectra. The paper growth-thickness limited the lateral size of the sample, so microspectroscopy was used to avoid spectral artefacts and contamination from the residual LDPE which could not easily be peeled away from the samples without damaging or destroying the GO sample.

FIGURE 1

\subsection{Visible light sample characterisation}

The samples were placed on $\mathrm{CaF}_{2}$ windows suitable for visible and IR transmission measurements. Polarised brightfield transmission images were obtained with a Zeiss 
Axioimager upright microscope (figure 2) confirming that the $\mathrm{C}=\mathrm{C}$ lattice planes are predominantly oriented in the plane of the bulk paper, which is the long sample axis in the images.

\section{FIGURE 2}

\subsection{FTIR microspectroscopy}

IR transmission absorption microspectroscopy was performed using a Bruker Hyperion 3000 infrared microscope coupled to a Vertex 80V FTIR spectrometer at beamline B22 of Diamond Light Source UK. In situ polarised visible observation of the sample was used to set the IR polariser axis with respect to the sample. A $50 \mu \mathrm{m}$ sized mid-band MCT single element detector was used along with a conventional (globar) source and broadband $\mathrm{KBr}$ beamsplitter. The sampled region was $\sim 20 \times 20 \mu \mathrm{m}$ determined by the square aperture via the $36 x$, NA 0.5 objective with rejection of stray light due to the small effective detector size $(\sim 14$ $\mu \mathrm{m}$ at $36 \mathrm{x}$ ). Typically one minute of scans (512 scans at scanner velocity $80 \mathrm{kHz}$ ) were averaged per spectrum with resolution $4 \mathrm{~cm}^{-1}$. The FTIR spectrometer was under vacuum, but the microscope was left in ambient conditions to preserve the hydration state of the sample.

\section{Results and discussion}

The IR spectrum of a hydrated edge-oriented GO paper sample with the polarisation parallel to the nominal sheet planes is shown in figure 3 . This spectrum compares well with spectra obtained in the usual geometry with the paper plane normal to the IR beam (i.e. also with the $E$ field essentially parallel to the sheets) from GO papers prepared by similar techniques [19]. Various IR bands have previously been assigned to different specific molecular groups based on different measurements of GO "multisheet" samples but we give the broad bond assignments in figure 3 .

\section{FIGURE 3}

Figure 4 shows polarised IR spectra, from the GO sample region shown in figure 2, in the O$\mathrm{H} / \mathrm{C}-\mathrm{H}$ stretch region $\left(4000-2500 \mathrm{~cm}^{-1}\right)$ for polarisation angles from 0 to 90 degrees with respect to the long axis of the sample (the nominal in-plane sheet axis). The spectra exhibit a clear dependence on the polarisation angle. Specifically, the relatively sharp shoulder at $3600 \mathrm{~cm}^{-1}$ is strongly oriented, peaking 90 degrees out of plane, and a weaker, broad, polarised component around $3250 \mathrm{~cm}^{-1}$ is also out of plane. These bands reduce again for extended measurements from 90 to 180 degrees (not shown), confirming that the sample has not been modified by the IR beam, and that the effects are purely due to polarisation.

\section{FIGURE 4}

The polarisation dependence of the fingerprint region is shown in figure 5 . The spectrum at around $1700 \mathrm{~cm}^{-1}$ is dominated by bands at $1630 \mathrm{~cm}^{-1}$ and $1740 \mathrm{~cm}^{-1}$ which show little polarisation. The weak band at $1820 \mathrm{~cm}^{-1}$ is strongly polarised out of plane. Between $1500-$ $800 \mathrm{~cm}^{-1}$, several bands show strong polarisation all out of plane whilst the weak band at $1255 \mathrm{~cm}^{-1}$ is polarised in plane.

FIGURE 5 
In sections 3.1 and 3.2 we discuss each band in figures 4 and 5 respectively. We evaluate our polarised measurements along with other results from the literature, and make band assignments which are summarised in table I.

\subsection{Bands in the $\mathrm{C}-\mathrm{H} / \mathrm{O}-\mathrm{H}$ stretch region, $2500-4000 \mathrm{~cm}^{-1}$}

The $\mathrm{O}-\mathrm{H}$ stretch band, shoulder at $3600 \mathrm{~cm}^{-1}$ in figure 4, has been assigned to adsorbed water [20,21], basal plane phenol $\mathrm{CO}-\mathrm{H}[8,17]$ (with possible contributions from 5 membered ring lactols [8]) and carboxyls $\mathrm{OCO}-\mathrm{H}$ [22]. In graphite oxide, the band moves on deuteration [17] confirming it is due to an $\mathrm{O}-\mathrm{H}$ bond. The shape of the band did not significantly change in a dehydration experiment on graphite oxide [17] leading to the authors assignment to structural $\mathrm{C}-\mathrm{OH}$. However, the band intensity did drop dramatically on dehydration, and approximately in proportion to the $\mathrm{O}-\mathrm{H}$ deformation they assigned to water at $1616 \mathrm{~cm}^{-1}$, whilst lower wavenumber bands assigned to $\mathrm{C}-\mathrm{OH}$ remained unchanged. The $3600 \mathrm{~cm}^{-1}$ band clearly increased with hydration level in a study of water dynamics in graphite oxide [20]. The polarisation measurements here show that the $3600 \mathrm{~cm}^{-1}$ band has a strong polarisation out of plane. For isolated GO sheets (in the absence of water) molecular modelling [8] shows that the $\mathrm{O}-\mathrm{H}$ stretch in basal plane phenols and 5 membered ring lactols would be strongly polarised in the lattice plane. It is unlikely that carboxyl groups would exhibit strong polarisation dependence, and the number of such edge groups should be relatively small. The polarised grazing incidence measurement of Mattson et al [21] showed an increase in the out of plane strength of the shoulder, in agreement with our findings, and assigned this to oriented $\mathrm{H}_{2} \mathrm{O}$. Furthermore, water adsorbed on $\mathrm{SiO}_{2}$ shows a similar band at $3520 \mathrm{~cm}^{-1}$ which is also preferentially polarised out of plane [23] and in general such high wavenumber bands are associated with free $\mathrm{O}-\mathrm{H}$. We conclude therefore that the $3600 \mathrm{~cm}^{-1}$ shoulder is most likely due to dangling out of plane $\mathrm{O}-\mathrm{H}$ bonds of adsorbed water.

The broad O-H stretch band around $3300-3600 \mathrm{~cm}^{-1}$ has been assigned to "hydroxyl groups of GO" [20], CO-H and water [8,17] with contributions from carboxyls [8], intercalated water $[21,24]$ and more generally as $\mathrm{O}-\mathrm{H}[25,26]$. In particular, a broad strong band at $3190 \mathrm{~cm}^{-1}$ in graphite oxide was clearly attributable to water and disappears under dehydration [17], and the same band increased significantly with hydration in a separate experiment [20]. In our data of figure 4, the broad feature around $3250 \mathrm{~cm}^{-1}$ does show some out of plane polarisation although this is only a small fractional change in the total absorbance. $3250 \mathrm{~cm}^{-1}$ is consistent with absorption by ordered or ice-like water which, for water adsorbed on $\mathrm{SiO}_{2}$, is known to exhibit preferential out of plane bond orientation [23]. It is hard to assign all the contributions to this spectral region, since we could be seeing weak polarisation of strong bands, strong polarisation of weaker components and combined positive and negative contributions. In isolated GO, the basal plane phenol and lactol O-H stretches would be expected to be in plane but this dependence is not observed as a strong polarised component. In polarised grazing incidence measurements [21], out of plane enhancement was also observed for the broad band $3300-3600 \mathrm{~cm}^{-1}$ and assigned to oriented water bonds. We assign the weak out of plane components of the $3250 \mathrm{~cm}^{-1}$ band to oriented $\mathrm{H}_{2} \mathrm{O}$.

\subsection{Bands in the fingerprint region, $800-2000 \mathrm{~cm}^{-1}$}

The $1740 \mathrm{~cm}^{-1}$ band is extensively known to derive from the carbonyl stretch and has been assigned to species at the edge of GO sheets, primarily carboxyls $[8,16,17,20,22,25,27-30]$ 
as well as contributions from ketones [8,16,17] and quinones [17]. Our polarised spectra (figure 5) show a small degree of out of plane polarisation, and is consistent with edge carboxyls. Mattson et al [21] observed the band at $1730 \mathrm{~cm}^{-1}$ both in normal and grazing incidence in reduced GO and, although the authors did not discuss the band, confirms that the band origin is due to tightly bound carbonyl groups and is not strongly polarised. The $\mathrm{C}=\mathrm{O}$ bonds from ketones and other modelled edge species [8] are expected to lie in plane, so they do not appear to contribute significantly to the spectrum.

The weak band at $1820 \mathrm{~cm}^{-1}$ has rarely been observed, and only as a very weak shoulder in previous normal incidence measurements of bulk graphene oxide [8] where it was assigned to $\mathrm{C}=\mathrm{O}$ from ketones/carboxyls. In the spectra of highly oxidised graphite the peak is present [17] but was not noted or assigned by the authors. From that work, the peak does not appear to change significantly on deuteration or dehydration [17] but, upon increasing the level of oxidation, intensifies much more rapidly than bands assigned to weakly bound $\mathrm{C}-\mathrm{OH}$ suggesting it originates from a tightly bound group. Our measurements clearly show that the $1820 \mathrm{~cm}^{-1}$ band has a strong out of plane polarisation, which is not consistent with the inplane stretch mode in ketones, or with carboxyls for which only a weakly polarised (out of plane) band was observed at $1740 \mathrm{~cm}^{-1}$. Vibrational modes for several carbonyl containing species have been modelled in $\mathrm{GO}$ [8] but for the considered cases, only in-plane stretch modes contribute at this wavenumber range. Further work is required to assign this band.

The strong band at $1630 \mathrm{~cm}^{-1}$ has been assigned to the $\mathrm{O}-\mathrm{H}$ deformation mode of residual adsorbed water in graphene and graphite oxides [17,20-22,32], unoxidised graphitic domains (aromatic $\mathrm{C}=\mathrm{C}$ stretch) [33] or a combination of the two $[8,26,27,31]$ along with possible smaller contributions from more exotic species [8]. The bandshape and intensity depends on the water content of the sample, and for high water contents (as in our samples) is dominated by water. Upon deuteration of graphite oxide [17], the band clearly moves and reduces in intensity on dehydration. Our measurements show that the band is weakly polarised out of plane, but is still the dominant component around $1630 \mathrm{~cm}^{-1}$ in all polarisations. This is consistent with the deformation mode of water, supporting our assignment of the $3600 \mathrm{~cm}^{-1}$ band, the previous assertion of Mattson et al [21] and the related polarised IR measurements [23] of water adsorbed on $\mathrm{SiO}$. The $\mathrm{C}=\mathrm{C}$ stretch may be present as a weak shoulder around $1590 \mathrm{~cm}^{-1}$ (figure 5), and we have observed this band more clearly in $\mathrm{GO}$ papers with low water content at a similar absorbance level to the $\mathrm{C}=\mathrm{O}$ stretch at $1740 \mathrm{~cm}^{-1}$. The weak shoulder does not appear to be highly polarised and is thus consistent with the polarised transmission measurement of rGO [21].

The spectral fingerprint region $1500-900 \mathrm{~cm}^{-1}$ has been one of the most controversial for band assignments in GOs and is due to the large number of convoluted bands as well as differences between samples produced by a variety of methods. The absolute absorbance at a given wavenumber will have contributions from numerous chemical groups, so discrimination relies on interpretation of band shapes e.g. a shoulder or sharp band can easily be distinguished from a broader band. By looking at the changes with polarisation, some of the complexity of the convolution can be removed.

The peak at $1425 \mathrm{~cm}^{-1}$ exhibits a relatively narrow band $\left(\sim 50 \mathrm{~cm}^{-1} \mathrm{FWHM}\right)$ superimposed on a broader band $\left(>150 \mathrm{~cm}^{-1}\right)$. The polarisation data show that the broader band has strong polarisation out of plane and is centred at $1410 \mathrm{~cm}^{-1}$, whilst the $1425 \mathrm{~cm}^{-1}$ band has weak polarisation. This observation is consistent with the grazing/normal incidence (polarised) 
data of Mattson et al [21] where the narrow $1425 \mathrm{~cm}^{-1}$ band was much stronger. The absorbance around $1425 \mathrm{~cm}^{-1}$ has generally been assigned to edge carboxyls $[21,26,29,33,34]$ but in several cases specifically the O-H deformation mode $[26,33]$ and in others the $\mathrm{C}-\mathrm{O}$ stretch [29]. The confusion here is understandable as the narrow band is near the peak of the broader band and a natural choice for assigning the global peak position in that region. Both bands are generally removed upon strong reduction (thermal or chemical) and in the study of Szabo et al [17] the band may be present as a shoulder on an intense, broad band at $1370 \mathrm{~cm}^{-1}$ assigned to CO-H. This band is significantly present and more clearly visible (though not mentioned by the authors) when the $1370 \mathrm{~cm}^{-1}$ band moves on deuteration. All these results are consistent with the interpretation of the $1425 \mathrm{~cm}^{-1}$ band as $\mathrm{C}-\mathrm{O}$ stretch in carboxyls, which would be expected to have weak polarisation and not move significantly on deuteration.

The broad band around $1300-1500 \mathrm{~cm}^{-1}$ (marked at $1410 \mathrm{~cm}^{-1}$ ) has been assigned to the O$\mathrm{H}$ bend in hydroxyl groups [16,17,20,22] or peripheral carboxyls [28] and has been observed to move significantly on deuteration, whilst under desiccation the band retains its strength [17]. In our polarisation measurements the band shows strong out of plane polarisation and this supports the assignment to the out of (sheet) plane $\mathrm{O}-\mathrm{H}$ bend of hydroxyl groups in basal plane phenols. In the previous polarised measurement of GO [21] the narrow $1425 \mathrm{~cm}$ ${ }^{1}$ band was relatively strong (in and out of plane) but similar behaviour from a broader component appearing much stronger out of plane is evident, yet not mentioned by the authors.

The in-plane polarised spectrum in the region $1200-1300 \mathrm{~cm}^{-1}$ (bottom curve in figure 5 for the edge-on microsample) shows at least two narrow convoluted bands superimposed on a broader absorbance. Our polarisation measurements reveal that there are in fact three narrow bands, with the central band at $1255 \mathrm{~cm}^{-1}$ polarised strongly in-plane, while the 1280 $\mathrm{cm}^{-1}$ and $1230 \mathrm{~cm}^{-1}$ bands are preferentially out of plane. A band around $1217-1245 \mathrm{~cm}^{-1}$ has been previously assigned to an epoxide stretch $[16,21,25,27,29,35]$, the C-O stretch in phenols $[17,26,33]$ or the in-plane bending mode of ketones [8]. In the work of Szabo et al [17] the narrow bands around $1250 \mathrm{~cm}^{-1}$ only emerge above the broad absorbance baseline after several stages of oxidation, whereas the stronger bands assigned to phenols appear at low oxidation and do not significantly increase on further oxidisation. The in-plane bending mode of ketones cannot be completely ruled out, but stronger in-plane modes would then be expected around $1500 \mathrm{~cm}^{-1}$ [8], which are clearly not observed in our experiments. A polarised measurement [35] of reduced graphene oxide found the $1235 \mathrm{~cm}^{-1}$ band to be inplane polarised. This previously measured band could be the same as our $1255 \mathrm{~cm}^{-1}$ but shifted due to reduction as it has about the same linewidth and polarisation dependence. In figure 5 , there is no clear evidence of the associated, broader out of plane band observed [35] at $1180 \mathrm{~cm}^{-1}$ which was attributed to the symmetric epoxide stretch, so this may be evidence against the entirety of the $1180 \mathrm{~cm}^{-1}$ band being from epoxide. However, a difference of $\sim 30 \mathrm{~cm}^{-1}$ between symmetric (out of plane) and asymmetric (in-plane) epoxide stretch bands would be consistent if the high energy side of that broadened peak (the peak absorbance [35] is already reached at $1200 \mathrm{~cm}^{-1}$ ) is only due to the symmetric epoxide stretch and the lower energy part of the peak due to other out of plane components (which could not be ruled out by the authors [35]).

A narrow band around $1280 \mathrm{~cm}^{-1}$ has been assigned to epoxides (for 5 layer GO but observed at $1265 \mathrm{~cm}^{-1}$ in multilayered samples [8]) and edge phenols [16]. The $1285 \mathrm{~cm}^{-1}$ 
band in our bulk GO papers is at least weakly out of plane polarised and so not due to edge phenols where the $\mathrm{C}-\mathrm{O}$ bond is in-plane. Other $\mathrm{C}-\mathrm{O}-\mathrm{C}$ bonds [8] from ether moieties could be responsible which would be consistent with the weak polarisation dependence.

A strong band peaking in the region $1050-1100 \mathrm{~cm}^{-1}$ has generally been assigned to the C-O stretch in alkoxy (phenol) groups. Although small contributions are expected [8] from various groups, by far the dominant contribution is already present on weak oxidation of graphite and does not increase significantly on further oxidation, in clear contrast to carbonyls $(\sim 1720$ $\mathrm{cm}^{-1}$ ) and epoxies (bands $\sim 1250 \mathrm{~cm}^{-1}$ ) and is removed easily on reduction $[8,21,22,30]$. The band does not change significantly on dehydration or deuteration [17]. In our experiments the band is observed at $1070 \mathrm{~cm}^{-1}$, and is highly polarised out of plane, which is consistent with the grazing incidence measurement of GO [21] and supports the generally accepted view that the band is predominantly due to basal plane phenols.

Finally, we observe a clear out of plane polarisation for the weak shoulder at $970 \mathrm{~cm}^{-1}$. Bands in the $850-1000 \mathrm{~cm}^{-1}$ region have been observed, but their interpretation is still a subject of debate. Several works assign bands in this region to epoxides at $920 \mathrm{~cm}^{-1}[20,30]$ or $850 \mathrm{~cm}^{-1}[16,8]$ and whilst a shoulder at $970 \mathrm{~cm}^{-1}$ is apparent in the spectra of Mattson et al [21] this was not discussed. In graphite oxide [17], a relatively strong and well resolved band at $968 \mathrm{~cm}^{-1}$ was broadly assigned (in a group with strong bands at $698 \mathrm{~cm}^{-1}$ and 828 $\mathrm{cm}^{-1}$ ) to skeletal $\mathrm{C}-\mathrm{C}$ and $\mathrm{C}-\mathrm{O}$ and did not depend on deuteration or dehydration. Polarised measurements of $\mathrm{rGO}$ [35] showed no features in the range $1000-800 \mathrm{~cm}^{-1}$ although other strong bands were observed and assigned to epoxides and carbonyls at higher wavenumbers with little absorbance due to weakly bound groups (as would be expected after reduction). We assign the $970 \mathrm{~cm}^{-1}$ band to out of plane polarised C-O stretch, and (summarising the other literature) most likely originating from weakly bound groups (ethers, phenols).

\section{Conclusion}

Infrared spectroscopy is a highly sensitive technique for chemical analysis of graphite and graphene oxides, yielding rich information from the oxide species and adsorbed molecules and highly complementary to Raman spectroscopy, which is extremely sensitive to the graphitic and disordered lattice modes. We measured polarised infrared transmission spectra through thin sections of edge oriented graphene oxide paper that allows direct quantification of oriented components without changing the optical setup or introducing optical standing wave effects (which is well known in normal and grazing incidence reflection geometries [36]). Numerous polarised bands were observed, assisting the infrared band assignment and structural analysis. Taking our results with complementary data from other experiments including thermal and chemical reduction, deuteration and dehydration, we tabulated the most likely band assignments and polarisations for the dominant spectral features. Structural analysis of GOs still remains a complex area of research due to the intrinsic variability of the materials dependant on production methods and environmental measurement conditions.

\section{Acknowledgements}

This work was partially supported by EPSRC grant no. EP/ F019882 and Diamond Light Source B22 access. CW acknowledges support through the Chinese Scholarship Scheme. 


\section{References}

[1] S. Stankovich, D.A. Dikin, G.H.B. Dommett, K.M. Kohlhaas, E.J. Zimney, E.A. Stach, R. Piner, S.T. Nguyen and R.S. Ruoff, Nature 442 (2006) 282-286.

[2] T. Ramanathan, A.A. Abdala, S. Stankovich, D.A. Dikin, M. Herrera-Alonso, R.D. Piner, D.H. Adamson, H.C. Schniepp, X. Chen, R.S. Ruoff, S.T. Nguyen, I.A. Aksay, R.K. Prud'Homme and L.C. Brinson, Nature Nanotechnology 3 (2008) 327-331.

[3] O.C. Compton, S.W. Cranford, K.W. Putz, Z. An, L.C. Brinson, M.J. Buehler and S.T. Nguyen, ACS Nano 6 (2012) 2008-2019.

[4] Q. Cheng, M. Wu, M. Li, L. Jiang, Z. Tang, Angewandte Chemie 52 (2013) 3750-3755.

[5] S. Park, R.S. Ruoff, Nature Nanotechnology, 4 (2009) 217- 224.

[6] Y. Si and E.T. Samulski, Nano Letters 8 (2008) 1679-1682.

[7] G. Eda, G. Fanchini and M. Chhowalla, Nature Nanotechnology 3 (2008) 270-274.

[8] M. Acik, G. Lee, C. Mattevi, A. Pirkle, R.M. Wallace, M. Chhowalla, K. Cho and Y. Chabal, J. Phys. Chem. C 115 (2011) 19761-19781.

[9] H. Liu, L. Zhang, Y. Guo, C. Cheng, L. Yang, L. Jiang, G. Yu, W. Hu, Y. Liu and D. Zhu, J. Mater. Chem. C 1 (2013) 3104-3109.

[10] S. Eigler, M. Enzelberger-Heim, S. Grimm, P. Hofmann, W. Kroener, A. Geworski, C. Dotzer, M. Röckert, J. Xiao, C. Papp, O. Lytken, H.-P. Steinrück, P. Müller and A. Hirsch, Advanced Materials 25 (2013) 3583-3587.

[11] Y. Wang, Z. Shi, Y. Huang, Y. Ma, C. Wang, M. Chen and Y. Chen, J. Phys. Chem. C 113 (2009) 13103-13107.

[12] M.F. El-Kady, V. Strong, S. Dubin and R.B. Kaner, Science 335 (2012) 1326-1330.

[13] M.Z. Hossain, J.E. Johns, K.H. Bevan, H.J. Karmel, Y.T. Liang, S. Yoshimoto, K. Mukai, T. Koitaya, J. Yoshinobu and M. Kawai Nature Chemistry 4 (2012) 305-309.

[14] J.W. Burress, S. Gadipelli, J. Ford, J.M. Simmons, W. Zhou, and T. Yildirim, Angew. Chem. Int. Ed. 49 (2010) $8902-8904$.

[15] W.S. Hummers, Jr. and R.E. Offeman, J. Amer. Chem. Soc. 80 (1957) 1339.

[16] A. Mathkar, D. Tozier, P. Cox, P. Ong, C. Galande, K. Balakrishnan,

A.L.M. Reddy and P.M. Ajayan, J. Phys. Chem. Lett. 3 (2012) 986-991.

[17] T. Szabó, O. Berkesi, P. Forgó, K. Josepovits, Y. Sanakis, D. Petridis and I. Dékány, Chem. Mater. 18 (2006) 2740-2749.

[18] S. Kim, S. Zhou, Y. Hu, M. Acik, Y.J. Chabal, C. Berger, W. de Heer, A. Bongiorno and E. Riedo Nature Materials 11 (2012) 544-549.

[19] C. Wang, M.D. Frogley, G. Cinque, L.-Q. Liu, A.H. Barber, Carbon 63 (2013) 471-477. 
[20] S. Cerveny, F. Barroso-Bujans, Á. Alegría and J. Colmenero, J Phys Chem C 114 (2010) 2604-2612.

[21] E.C. Mattson, H. Pu, S. Cui, M.A. Schofield, S. Rhim, G. Lu, M.J. Nasse, R.S. Ruoff, M. Weinert, M. Gajdardziska-Josifovska, J. Chen and C.J. Hirschmugl, ACS Nano 5 (2011) 9710-9717.

[22] Z. Hu, Y. Chen, Q. Hou, R. Yin, F. Liu and H. Chen, New J. Chem. 36 (2012) 1373-1377.

[23] A.L. Barnette, D.B. Asay and S.H. Kim, Phys. Chem. Chem. Phys. 10 (2008) 49814986.

[24] C. Chen, M. Long, M. Xia, C. Zhang and W. Cai, Nanoscale Res. Lett. 7 (2012) $101-$ 105.

[25] N.H. Kim, T. Kuila and J. H. Lee, J. Mater. Chem. A 2 (2014) 2681-2689.

[26] Y. Xu, H. Bai, G. Lu, C. Li and G. Shi, J. Am. Chem. Soc. 130 (2008) 5856-5857.

[27] Z. Ji, G. Zhu, X. Shen, H. Zhou, C. Wu and M. Wang, New J. Chem. 36 (2012) 17741780 .

[28] T. Kar, S. Scheiner, U. Adhikari and A.K. Roy, J. Phys. Chem. C 117 (2013) 1820618215.

[29] S. Park, D.A. Dikin, S.T. Nguyen and R.S. Ruoff, J. Phys. Chem. C Lett. 113 (2009) 15801-15804.

[30] L.J. Cote, R. Cruz-Silva and J. Huang, J. Amer. Chem. Soc. 131 (2009) 11027-11032.

[31] C. Galande, A.D. Mohite, A.V. Naumov, W. Gao, L. Ci, A. Ajayan, H. Gao, A.

Srivastava, R. Bruce Weisman and P.M. Ajayan, Sci. Rep. 1, 85; DOI:10.1038/srep00085 (2011).

[32] A.M. Dimiev, L.B. Alemany and J.M. Tour, ACS Nano 7 (2013) 576-588.

[33] J. Zhu, C.M. Andres, J. Xu, A. Ramamoorthy, T. Tsotsis and N.A. Kotov, ACS Nano 6 (2012) 8357-8365.

[34] A.J. Page, C.-P. Chou, B.Q. Pham, H.A. Witek, S. Irle and K. Morokuma Phys. Chem. Chem. Phys. 15 (2013) 3725-3735.

[35] E.C. Mattson, J.E. Johns, K. Pande, R.A. Bosch, S. Cui, M. Gajdardziska-Josifovska, M. Weinert, J.H. Chen, M.C. Hersam and C.J. Hirschmugl, J. Phys. Chem C Lett. 5 (2014) 212219.

[36] J. Filik, M.D. Frogley, J.K. Pijanka, K. Wehbe and G. Cinque, Analyst 137 (2012) 853861. 
Table I. Summary of measured IR bands from graphene and graphite oxides. IP and OOP refer to in-plane and out of plane oriented components.

\begin{tabular}{|c|c|c|c|c|c|}
\hline $\begin{array}{l}\text { Band } \\
\left(\mathrm{cm}^{-1}\right)\end{array}$ & $\begin{array}{l}\text { Previous } \\
\text { assignments } \\
{[8,15,16,19-} \\
21,23-34]\end{array}$ & $\begin{array}{l}\text { Polarisation } \\
\text { (this work) }\end{array}$ & $\begin{array}{l}\text { Moves on } \\
\text { deuteration } \\
{[16]}\end{array}$ & $\begin{array}{l}\text { Hydration } \\
\text { dependent } \\
{[16,19]}\end{array}$ & Assignment \\
\hline 3600 & $\begin{array}{l}v(\mathrm{O}-\mathrm{H}) \mathrm{H}_{2} \mathrm{O}, \\
\mathrm{COOH}, \mathrm{C}-\mathrm{OH}\end{array}$ & Strong OOP & YES & YES & $\begin{array}{l}v(\mathrm{O}-\mathrm{H}) \mathrm{H}_{2} \mathrm{O} \text { free } \\
\text { bond }\end{array}$ \\
\hline 3200 & $\begin{array}{l}v(\mathrm{O}-\mathrm{H}) \mathrm{H}_{2} \mathrm{O}, \\
\mathrm{COOH}, \mathrm{C}-\mathrm{OH}\end{array}$ & Weak OOP & YES & YES & $\begin{array}{l}v(\mathrm{O}-\mathrm{H}) \text { ice-like } \\
\mathrm{H}_{2} \mathrm{O}\end{array}$ \\
\hline 1820 & $\begin{array}{l}v(\mathrm{C}=\mathrm{O}) \text { ketone, } \\
\mathrm{COOH}\end{array}$ & Strong OOP & $\mathrm{NO}$ & $\mathrm{NO}$ & Unassigned \\
\hline 1740 & $\begin{array}{l}v(\mathrm{C}=\mathrm{O}) \text { ketone, } \\
\mathrm{COOH}\end{array}$ & Weak OOP & $\mathrm{NO}$ & $\mathrm{NO}$ & $v(\mathrm{C}=\mathrm{O}) \mathrm{COOH}$ \\
\hline 1630 & $\begin{array}{l}\delta(\mathrm{O}-\mathrm{H}) \mathrm{H}_{2} \mathrm{O} \\
v(\mathrm{C}=\mathrm{C})\end{array}$ & Weak OOP & YES & YES & $\delta(\mathrm{O}-\mathrm{H}) \mathrm{H}_{2} \mathrm{O}$ \\
\hline 1425 & $\begin{array}{l}v(\mathrm{C}=\mathrm{C}) \\
\delta(\mathrm{O}-\mathrm{H}), v(\mathrm{C}-\mathrm{O}) \\
\mathrm{COOH}\end{array}$ & None & NO & $\mathrm{NO}$ & $v(\mathrm{C}-\mathrm{O}) \mathrm{COOH}$ \\
\hline 1410 & $\begin{array}{l}\delta(\mathrm{O}-\mathrm{H}) \text { basal } \\
\text { plane } \mathrm{CO}-\mathrm{H}, \\
\mathrm{COOH}\end{array}$ & Strong OOP & YES & $\mathrm{NO}$ & $\begin{array}{l}\delta(\mathrm{O}-\mathrm{H}) \text { basal } \\
\text { plane } \mathrm{CO}-\mathrm{H}\end{array}$ \\
\hline 1280 & $\begin{array}{l}v(\mathrm{C}-\mathrm{O}) \mathrm{C}-\mathrm{OH}, \\
\text { epoxy, ethers }\end{array}$ & Weak OOP & $\mathrm{NO}$ & $\mathrm{NO}$ & $\begin{array}{l}v(\mathrm{C}-\mathrm{O}) \mathrm{C}-\mathrm{OH}, \\
\text { epoxy, ethers }\end{array}$ \\
\hline 1255 & $\begin{array}{l}v(\mathrm{C}-\mathrm{O}) \text { epoxy, C- } \\
\mathrm{OH}, \mathrm{COOH}, \\
\delta(\mathrm{C}=\mathrm{O}) \text { ketone }\end{array}$ & Strong IP & $\mathrm{NO}$ & $\mathrm{NO}$ & $v_{\text {as }}(\mathrm{C}-\mathrm{O})$ epoxy \\
\hline 1230 & $\begin{array}{l}v(\mathrm{C}-\mathrm{O}) \text { epoxy, C- } \\
\mathrm{OH}\end{array}$ & Strong OOP & $\mathrm{NO}$ & $\mathrm{NO}$ & $v_{s}(\mathrm{C}-\mathrm{O})$ epoxy \\
\hline 1070 & $\begin{array}{l}v(\mathrm{C}-\mathrm{O}) \mathrm{C}-\mathrm{OH}, \\
\text { ethers, } v(\mathrm{C}-\mathrm{C})\end{array}$ & Strong OOP & $\mathrm{NO}$ & $\mathrm{NO}$ & $\begin{array}{l}v(\mathrm{C}-\mathrm{O}) \text { basal } \\
\text { plane } \mathrm{C}-\mathrm{OH}\end{array}$ \\
\hline 970 & $\begin{array}{l}v(\mathrm{C}-\mathrm{O}), v(\mathrm{C}-\mathrm{C}) \\
\delta(\mathrm{O}-\mathrm{H}) 5 \text { member } \\
\text { ring lactol }\end{array}$ & Strong OOP & $\mathrm{NO}$ & $\mathrm{NO}$ & $\begin{array}{l}v(\mathrm{C}-\mathrm{O}) \\
\text { unassigned }\end{array}$ \\
\hline
\end{tabular}




\section{Figure Captions}

Figure 1. Scanning electron micrograph of the fracture surface typical to our GO papers, showing a strong degree of orientation of the GO sheets in the plane of the paper.

Figure 2. Polarised visible light brightfield images of the sectioned edge-on GO paper electrostatically bonded to LDPE. The arrows indicate the polarisation direction of the electric field $E$ and the subscript refers to the angle with respect to the nominal $G O$ planes. Scale bar $100 \mu \mathrm{m}$. Inset: geometries for microtomy with LDPE clamp and for IR microspectroscopy of edge on samples.

Figure 3. Polarised IR transmission spectrum for edge-oriented GO microsample. The polarisation axis is parallel to the nominal graphene oxide planes.

Figure 4. Polarised IR transmission spectra in the $\mathrm{O}-\mathrm{H} / \mathrm{C}-\mathrm{H}$ stretch region for the edge oriented graphene oxide microsample shown in figure 2. The polarisation angle with respect to the plane of the paper angle is shown, and increases by $10^{\circ}$ per spectrum. All spectra have been offset on the vertical axis for clarity.

Figure 5. Polarised IR transmission spectra in the fingerprint region in the same conditions as figure 4 . 